\title{
'This is a solar-powered website, which means it sometimes goes offline': a design inquiry into degrowth and ICT
}

\author{
Roel Roscam Abbing \\ roel.roscam-abbing@mau.se \\ School of Arts and Communication (K3), Malmö Universitet \\ Malmö, Sweden
}

\begin{abstract}
This paper describes how principles derived from degrowth can be a useful heuristic for designing an ICT system within energy limits. It does so by discussing the design choices behind https://solar.lowtechmagazine.com, an ongoing design research project that set out to build a 'low-tech website'. This research resulted in a design which is lightweight, tailored towards older and lower-powered devices, is powered by off-grid solar energy and thus designed with energy scarcity in mind. The project shows that values and frameworks theorized within the Computing within Limits community are technically applicable to practices of web development but also identifies hurdles to their more widespread applicability.
\end{abstract}

\section{KEYWORDS}

Degrowth, Design Research, Web Development, Sustainable HCI

\section{Reference Format:}

Roel Roscam Abbing. 2021. 'This is a solar-powered website, which means it sometimes goes offline': a design inquiry into degrowth and ICT. In LIMITS '21: Workshop on Computing within Limits, fune 14-15, 2021.

\section{INTRODUCTION}

This article describes the design considerations behind https://solar.lowtechmagazine.com, an example of a transitional system which goes to great lengths to reduce the energy footprint associated with hosting web content. It is an example on a micro-scale, but at the same time is an in-vivo example with real use. The website attracts around one million unique visitors each year and has been in operation since the fall of 2018. It has been designed as an experiment and as a design provocation, consequently the project has received considerable media attention over the years [4]. In that process, it has sparked and influenced discussions among designers and practitioners working on the intersections of sustainability and web development. As one of the designers of the project, I've written this paper to demonstrate that the principles and theories developed in the LIMITS community are technically and theoretically implementable and that, while there significant hurdles remain for their more widespread practical applicability, these theories are generative to more in-depth design work.

Permission to make digital or hard copies of part or all of this work for personal or classroom use is granted without fee provided that copies are not made or distributed for profit or commercial advantage and that copies bear this notice and the full citation on the first page. Copyrights for third-party components of this work must be honored. For all other uses, contact the owner/author(s).

LIMITS '21, fune 14-15, 2021,

(C) 2021 Copyright held by the owner/author(s).
While https://solar.lowtechmagazine.com is an in-vivo experiment, it is nevertheless a highly particular and controlled environment which is not reflective of the current status quo of web development and digital design. Therefore, not all the aspects of this design, in particular the off-grid solar server as a hosting environment, are applicable to more conventional set-ups such as shared hosts and virtual private servers.

At the same time, however, the radical shifts of this redesign were mostly based on techniques already widely available, and can therefore be applied in other more conventional setups. Most of these techniques have been sourced from blogs and guides listing best practices in regard to web performance and usability. By themselves these techniques do not necessarily reduce energy footprints and might, in fact, be conducive to rebound effects. This article thus argues that principles derived from degrowth can serve as a useful and necessary heuristic when it comes to assessing and implementing techniques to reduce energy footprints.

Degrowth is a concept which at the core questions the need and sustainability of economic growth. It looks for pathways to 'degrow' (Western) economies by reducing the throughput of energy and resources in society while improving the quality of life [14]. It should be said that this is a narrow characterization of degrowth but one that, for the sake of brevity and scope, is the one that will be developed in this article. Within the degrowth community itself exist a multitude of concerns and positions around for example democratization, equity and culture [12]. This has lead degrowth to be characterized both as a 'movement of movements', spanning academic disciplines, social movements, and practices and as a 'concept in the making' for the fact there is not a single definition yet [23].

Of particular interest for this article is the relation of degrowth to technology, and to ICTs specifically. This relation remains ambivalent within the degrowth community itself [15]. Contributions on the intersections of ICTs and degrowth have for example covered how lifestyle movements around smartphones might contribute to degrowth by fostering sustainable consumption [12]. Within degrowth research, case studies of engagement with concrete 'lowtech' practices and technologies exist [11], but ICT practices, such as web development, have not been approached similarly. Within the HCI community and specifically SHCI and ICT4S links between degrowth and ICTs have been made in the more expanded notion of degrowth [25] or more implicitly as the with the question of infrastructural reduction [24]. This article, by taking a more narrow reading of degrowth, focused on reducing throughput within a system whilst improving the quality of using it, therefore also adds to the discourse on degrowth and ICTs by providing the example 
of the transitional system described. In particular, it will argue that principles derived from degrowth are a useful heuristic for guiding the design of web environments that want to limit energy footprint.

To summarize, this article demonstrates what a transitional system based on LIMITS can look like. In doing so, it asks how degrowth can be applied to the design of web technology.

\section{INTRODUCING LOW-TECH MAGAZINE}

Low-tech magazine is an on-line publication that since 2007 cast 'doubts on progress and technology'. The magazine publishes around 12 long-form articles a year on three topics: 'obsolete technologies', 'high-tech problems', and 'low-tech solutions'. These topics on technology, energy use and history themselves cover a wide range of subjects such as the built environment, healthcare, transportation, heating and more recently ICT. Whereas 'obsolete technologies' covers past and forgotten technologies, 'high-tech problems' problematizes notions of technical progress and 'low-tech solutions' investigates the potential of combining 'old technology with new knowledge and new materials, or [..] old concepts and traditional knowledge [with] modern technology.' [2]

One of the aspects of the magazine is that it has a hands-on approach to the topics it covers. Thinking about renewable energy and energy security are informed not only by historical examples and academic literature, but also by converting the office energy supply into a largely off-grid solar-powered one. Similarly, articles on thermal insulation of bodies [16] and arguments on heating people rather than homes [17] are informed by a lifestyle without central-heating in addition to literature. Following this method of working, the long overdue redesign of the magazine's website called for a research project, which started in 2018.

The direct opportunity for the project arose out of a chance meeting between all collaborators on this project. The magazine had been approached by designers Marie Otsuka and Lauren TraugottCampell, who as part of their internship at the magazine, wanted to propose a new design for the website based on low-tech principles. Not much later I joined the conversation and as a team we managed to extend their work and develop it into a holistic design.

Aside from this chance meeting, the question of a thorough reevaluation of the old Low-Tech Magazine web page had been in the air for some time. Especially considering that, in a tongue-incheek manner, the magazine often was asked why it has a website at all, if it is about low-tech? While easy to dismiss as a joke, it is a powerful question nonetheless because it begs another: What could make a website low-tech?

\section{3 'WHAT IS A LOW-TECH WEBSITE?'}

The guiding principle for the low-tech website was the aim to 'radically reduce the energy use associated with accessing [the magazine's] content' [19]. In web infrastructure, energy use occurs at various points: at the point of the server, when the clients request content and at the intermediary hops between the server and the client. One of the challenges is, that in most configurations, web designers have fairly limited control over all three, which makes it less evident what possible points of intervention are.

On top of that, the energy footprint considered in this project, was not only that of primary energy use in operation but also of the embedded energy of the equipment. As a result the research process was aimed at figuring out a holistic strategy to radically reduce the energy use associated with the website through a combination of graphical, technical and conceptual approaches.

Our resulting design is based around a static website. This website is hosted on low-powered hardware with a low-energy chipset originally developed for smartphones, that uses $2.5 \mathrm{Wh}$ at most. The choice for the static website was made in order for the system to work well in conjunction with the low-powered hardware and a consumer internet connection. The whole system is powered by an off-grid solar system in Barcelona, Spain. The off-grid solar installation consists of a $30 \mathrm{~W}$ solar panel and a $168 \mathrm{Wh}$ lead-acid battery [21]. Given maximum power usage, the battery drains after three days. A rainy or cloudy week means the system will go off-line until the sun comes out again. The energy and weather conditions the system is subject to are explicitly communicated as part of the website's design.

This setup allowed for a holistic approach which spans both points of intervention traditionally associated with either frontend and back-end development work. While this particular setup allowed us to measure the effects of our design's energy use on the server, there is little that can be done to measure their effect in the wider network. Therefore, we guided the rest of our decisions based on a set of rules of thumb derived from degrowth principles.

\section{CHALLENGING THE NEED FOR AVAILABILITY}

Transitioning from a society predicated on unsustainable perpetual growth requires both limiting absolute throughput of materials but also adjusting long-held assumptions. This section explores how shifting away from a model of 24/7 availability of web services allows one to degrow the required infrastructure associated and make them self-sufficient [13] regarding their energy use.

Considering the fact that the Low-Tech Magazine office already partly operated on an off-grid solar system, it was a logical step to use that existing infrastructure as a basis for the redesign. Offgrid renewable systems do not feed into the main power grid and conversely can also not draw from it when there are shortages. Going off-grid thus grounded the redesign in concrete and material energy limits and, crucially, made the infrastructure dependent on the intermittency of the weather.

On a fundamental level, intermittent renewable energy is at odds with the cornucopian model of computing [24], which relies on always being available. While this tension can be addressed with technical interventions such as increasing the battery and solar capacity, these interventions will also increase the energy footprint and complexity of the overall infrastructure. Instead, for many non-critical systems and applications, designing for lower availability provides pathways to reduce the energy footprint of such infrastructure.

Prior articles in Low-Tech Magazine argued that it is much more feasible for systems to run fully on renewable energy if assumptions on energy security are redefined [20] and energy demand is tied to energy availability, as has been the case historically [18]. Concretely, the main conceptual intervention to come out of this was to challenge the necessity of a high 'uptime', or availability. 


\subsection{Understanding the costs of uptime}

Being available $100 \%$ of the time requires substantially more effort than one would initially consider, especially when using intermittent power sources.

On the other hand, an availability of $90 \%$ of the time, which roughly equals one month a year, is relatively easy to achieve with off-grid solar. Increasing that availability further, however, leads to rapidly increasing (embodied) energy requirements all the while diminishing absolute gains in uptime. The logic behind this becomes palpable if one looks at an expression common in site-reliability engineering, where 'five nines' or $99.999 \%$ is the highest standard for availability. Going from $90 \%$ ('one nine') to 95\% uptime, means a halving of the downtime (from $10 \%$ to 5\%). Moving from $95 \%$ to $97 \%$ and $98 \%$ to $99 \%$ ('two nines') are also each a halving of the down time [7]. Going from 'one nine' to 'five nines' availability requires 11 such halvings, an exponential decrease of absolute uptime at a substantial increase of infrastructure footprint. That is because increasing the uptime in to the higher ranges of 'nines' requires an increased capacity of generation and storage of renewable energy, which need to cover the worst-case scenarios in terms of seasonal fluctuations. In addition, availability is not only predicated on energy availability but also the availability of other system components. Therefore it will also require a redundancy of upstream network connections, server hardware and additional monitoring infrastructure.

In other words, allowing for the possibility that the content is unavailable some of the time, but available the vast majority of the time, decreases both the potential complexity of the infrastructure and also its energy footprint. Since the launch of the website in 2018, the yearly uptime has been around $95 \%$. That has remained constant despite the fact that the site attracts more visitors year after year, that the number of sites on the server has grown as translated editions of the magazine have been migrated over to the new design and that both the size of the battery and solar panel have been reduced from the original design. That the uptime remained roughly constant over the years despite higher utilization and lower power availability indicates that the 'problem' of the remaining $5 \%$ downtime can be addressed by other means with less energy impact.

In the case of the design of https://solar.lowtechmagazine.com, the downtime is addressed in two ways: by setting expectations and by providing means for off-line reading. Off-line reading is part of a set design interventions aimed towards hetereogenous use and is discussed further on. With regards to setting expectations, one of the most distinctive design elements of the site is the presence of a battery meter. This meter turns the page's background from a pastel yellow to a pastel blue as the percentage of charge in the battery drops. Additionally, the page provides a weather forecast at the server's location for that day and the coming days. These two elements both communicate the materiality of the underlying infrastructure and set expectations for future availability. More importantly, they attempt to shift the perception of unavailability away from being an error and a disruption towards unavailability being an acceptable part of the ebb and flow of the system.

In all fairness, the fact that the project concerned a redesign of an existing site meant that there was an indication of the amount and type of traffic expected but also the type of use. The website publishes a new long-form article roughly once a month, meaning that the tempo of usage of the site is slow to begin with. Similarly, being able to communicate future availability is predicated on access to the server hardware. This way of designing for unavailability is more workable for this particular project and it should be recognized that this is more difficult to achieve for other projects. Despite that, it shows that changing norms and expectations around both web infrastructure and renewables can lead to significant reduction of energy footprint at negligible impact to readers.

\section{APPLICATION OF COMMON USABILITY AND PERFORMANCE PRINCIPLES WITH DEGROWTH AS A HEURISTIC}

While the above-mentioned design intervention is very particular to the situation of Low-Tech Magazine, the other design interventions at the core of https://solar.lowtechmagazine.com are much more reproducible in conventional setups. In fact, most of these interventions and design decisions are neither novel nor unknown within web design communities. That is because most of them were sourced from a variety of literature well known to most web developers: literature on usability, SEO (search engine optimization) and web performance optimization.

On the technical side, common techniques encountered in such literature include limiting the use of rich media (images, fonts and video); the reduction of resolutions and file sizes; the compression of text-based responses such as HTML, CSS and JS which are thus typically sent over the network as gzip-compressed files; reducing the amount of requests between client and server; the caching of responses either on the client's browser cache, in the memory of the server or through an external party such as a Content Delivery Network. On the design side it includes steps such as keeping a clear semantic structure within the HTML, improving the usability of the site by making the content easy to find and read, sticking to more conventional layouts and prioritizing the support of different browsers, devices and network speeds. However, none of these steps by themselves necessarily lower the energy footprint of the entire system and can easily lead to rebound effects or increase the total footprint of the system depending how they are employed.

\subsection{How can degrowth be applied to web development?}

Therefore, the team chose to evaluate and implement all the recommendations and practices found in that body of literature based on the degrowth-inspired principle of limiting the amount of energy and material throughput in the system, whilst improving the quality of it. Again, the system here is considered to be the server itself, the client devices and the network in between. Concretely, this meant to limit:

- the amount of bytes transferred over the network

- the use of client-side computation and processing

- the use of server-side per-request computation

- the use of third party services

These limits are based on the fact that, as a web designer, it is not possible to know exactly what the energy impacts are on the 
various parts of the system. One can, however, logically reason that the use of less computational processing leads to less use of energy. By extension, the speed at which a computer or network of computers can solve a particular task, such as rendering a web page or transporting files, can be considered a proxy for resource usage [5]. If these tasks can be sped up by decreasing the sizes of files or limiting the amount of computation, i.e. 'degrowing' the computation required, these can be considered to lower the energy footprint.

\subsection{Increasing the quality of experience as a consequence of degrowing}

In the case of web development, the aim to improve the quality can be considered to mean improving the quality of user experience. While quality is obviously hard to grasp, regarding the interplay of processing speed and energy expenditure, quality metrics such as Google's 'Web Vitals' [6] can be useful. These metrics for example reflect the time it takes for the bulk of the web page to have been rendered or the time the page is unresponsive due to loading. Additionally, such tools track the time it takes for a page to have completely finished loading. The design team found that this design not only scored extremely well on these metrics $[9,19]$ but one could argue that achieving good scores on these metrics, whilst simultaneously lowering the energy footprint, might in fact be predicated upon using degrowth heuristics.

\subsection{Why heuristics?}

In other words, following the heuristic is conducive to good scores on such quality metrics, whereas aiming to just score well on the metrics can also easily lead to a ballooning of the footprint and the complexity of the infrastructure. To give a more concrete example: the load times of heavy pages can be decreased by storing copies of these pages close to the clients requesting them, shortening the distance of content to client, through a reliance of globally distributed Content Delivery Networks. However, such a move implies an infrastructural expansion [24] which comes with associated resource use. When one aims to drastically reduce the size of these pages instead, one will also bring down the load times due to aforementioned effects. However, it will happen in a way that does not require additional infrastructure. In both cases, the exact implications for the energy footprint are very hard to measure, but it can be inferred instead.

In an environment where hardware is commonly virtualized, the environmental footprint can be difficult to ascertain. It is exactly because of this uncertainty that a notion of a heuristic is proposed: a set of general guidelines and arguments to guide future design work are more useful than setting absolute targets. Especially when these targets are hard to measure. Instead, following the general direction provided by the heuristic, that is, reducing the throughput of energy and materials in the system, is sufficient as it also leads to better scores on the above-mentioned quality metrics but does not entail infrastructural expansions.

In practice, in the case of https://solar.lowtechmagazine.com, following the heuristic meant that some recommendations such as caching and compression could be used, whereas others such as the use of (compressed) video or third party caching services could not. An exhaustive description of design considerations has been documented in earlier publications as part of the project $[19,22$, 26], and will not be repeated in this article. However, this article will highlight two distinct design interventions which warrant further attention: using techniques to limit computation in time and place and practices that support a heterogeneity of devices and connection speeds.

\section{LIMIT COMPUTATION IN TIME AND PLACE USING STATIC SITES}

One of the more consequential decisions for our design was to use so-called static sites rather than conventional dynamic websites. With static sites the entire website is generated once and served as a set of documents that exist on the server's storage. Dynamic sites are a system where typically every request to the web server leads to a database query and the regeneration of a specific page. In other words, static sites are a model where websites are batch-processed collections of documents served from disk, rather than either clientside or server-side apps generating pages in real time. In that sense, they hark back to a more historical model of web development whose output was files rather than applications. The benefit of static sites is that they load much faster and perform well under increased load, as the only significant bottle-neck is the speed at which the files can be read from storage. Dynamic sites, on the other hand, have the benefit that they allow for things such as interactive forms and user generated content. Dynamic sites thus allow for a significant expansion of a web page's features which explains why these are much more common. However, these features are not always necessary and come at a cost in performance, which is noticeable in the form of increased load times or websites becoming unavailable if they have too much traffic. On top of that they require much more maintenance and updates than static sites do.

\subsection{Timing resource use}

One particular advantage of a static site is that it allows to shift the moment of calculation to a moment when energy is available. In the case of a system that is based on the real-time processing of requests, energy usage as a result of that processing might peak at times of scarcity of energy or spare processing power. Batch processing allows for demand flexibilization [13], meaning that the computation occurs when energy is available and that the results of the computation are stored and also available when energy is scarce. In the case of our design, this demand flexibilization covers not only the rendering of web pages and feeds, which for the main English-language website and the 10 translated sites takes about 70 minutes. Demand flexibilization is also used for all other computationally intensive tasks: image processing, the pre-compression of all generated web pages, the processing of web page statistics, the making of backups and the execution of system updates. They happen when energy is plentiful and are postponed when it is not.

\subsection{Localizing resource use}

This design thus locates the bulk of computation on the server and times it to happen during a time when energy is plentiful. Being able to do this precluded the extensive use of so called client-side programming languages such as JavaScript. While very common 
in contemporary web development and extremely versatile in their application, the heuristic simply indicated against using them for the majority of the work. The reason for this is that, in essence, client-side programming means that the code is executed on each visitor's individual machine. A thousand visitors means the same code is processed a thousand times, rather than calculating once and distributing the results. While this might be necessary or desirable to produce individualized results (for example by allowing one to retrieve personalized information or offering different levels of interactivity) client-side languages are also used in order to just deliver content or generate pages. When used in this way their advantage is that they move computation which otherwise would have happened on the web server towards the clients, which means the web server is able to handle much more traffic this way. Externalizing the cost of processing towards the clients like this, however, increases the total amount of computation necessary with each visitor. At the same time, even simple websites can not do without client-side processing if they want to use novel interactions. https://solar.lowtechmagazine.com uses them to display the battery meter, for instance.

So, by making a choice for which development tools to use, one can reason on how, where and in what capacity computation happens in such a system. As a result, one can try to limit computation in time and place to make sure it does not happen all over the system and that it does not happen redundantly.

\section{DESIGNING FOR A HETEROGENEOUS USE}

Whereas the previous section considered how computation can be limited in time and place by using static site generators and demand flexibilization, this section describes how that facilitates supporting a heterogeneous use. That is usage, by a heterogeneity of browsers, devices and connection speeds which deviate from the cornucopian ideal.

\subsection{Slow networks and old devices}

To limit the throughput of materials in a system one should also consider software's ability to drive or diminish obsolescence. The expansion of unnecessary features and inefficiencies within software drive hardware obsolescence by making older hardware increasingly unsuitable. [13]

To counteract this, the redesign was conceptualized to work specifically for 10-15 years old devices and very slow networks. This decision was partly informed by using these older devices ourselves and noticing how popular websites would slow these machines down and make them hard to use. Designing with such old devices in mind meant that the design would work well on these old devices and load reasonably on slow networks, but would perform even better on modern devices and fast networks. This as opposed to a design that works well on contemporary devices and works badly or not at all on older ones. The same decisions to limit the amount of bytes transferred over the network and to limit the use of client-side computation meant that this was perfectly possible and took little extra effort. In fact, the use of a technique that produces websites as pre-computed documents, a technique that was arguably already already outdated when these 10-15 year old machines were made, means these older machines are well suited for it.

The ability to keep hardware, be it phones or laptops, up to date requires affluence. Therefore, creating designs which don't obsolete old machines or slower networks are ways in which to increase qualities in degrowth's more expanded notions, in terms of access and equity. Both Facebook [1] and Google's Gmail [10] offer special versions of their applications which limit both client side calculation and the total bytes transferred over the network. They do this to support older, less performant devices and slow connections. Similarly, Instagram introduced features to turn off the automatic loading of resources as a feature 'for emerging markets where data plans and internet speeds might be limited' [3]. The fact that the same services can be made to work without the need for as much data or computational capacity shows that degrowing these platforms is possible. The fact that it is necessary for these platforms to do this in order to reach certain audiences, arguably at the expense of engagement and fine-grained data collection, shows that issues of performance are also political in nature.

\subsection{Off-line reading}

Aside from designing for older devices, solar.lowtechmagazine.com was also designed for 'off-line reading'. This was done in two distinct ways: by making aggressive use of the visitor's browser cache and by offering the entire archive as an RSS feed.

Using the browser cache is part of the common performance optimizations mentioned previously. It is a way to automatically store resources (such as images or style sheets) once they've been downloaded as part of a requested page. Browser caches are used to speed up the browsing experience when loading another page which contains the same resources. These resources get loaded from the local cache rather than requested over the network again. It is a way of speeding up load times and of saving energy. Items stored in the cache can be given an expiration date which helps the browser decide when to request resources over the network and when to use the cache. In our design, aside from the front page, caches do not expire. The front page has an expiry of a month, roughly coinciding with the publication tempo. Caches however can also be used when the server is temporarily unavailable. Therefore, every article that has been downloaded essentially becomes part of a personal archive for offline reading.

Similarly, the website can be configured to return the entire archive of articles in the way of an RSS feed and in this way act as an off-line archive. RSS (Really Simple Syndication) allows readers to subscribe to websites using 'feed readers' and receive new articles without visiting the web page, these feed readers then keep a copy of the article which can be accessed when the reader is off-line. All 118 English language articles currently on the website fit in a single compressed feed document totaling $1.18 \mathrm{MB}$, or almost half the size of a single median web page in 2021 [8]. However, this file does not include any of the 1486 images which illustrate the articles. These images are requested separately as readers open up each article in their feed reader and these images weigh $52.8 \mathrm{MB}$ in total. 


\section{CONCLUSION}

This article has described a practical example of how web infrastructure can be designed to leverage concepts discussed within the LIMITS community in order to radically diminish the energy associated with accessing a website. In addition, it has argued that, while it can be challenging as a web developer to know which design decisions lower energy impact, using a set of heuristics derived from principles of degrowth can provide practical ways to doing so. Furthermore, the design demonstrated that 'degrowing' web systems is an avenue to simultaneously lower the energy footprint and achieve significant performance gains which in turn have an effect on access and equity.

One of the limitations of the design discussed is that it is highly particular and not reflective of the most common uses and needs of contemporary web design, such as handling user input. Furthermore, the types of tools this website is dependent on, such as the static site generator, means that the design is inaccessible for those without extensive technical knowledge. At the same time, the heuristic proposed in this article, on the basis of which the design was made, is applicable to the design of other web systems as well. Therefore, the design proposed is not to be taken as a blueprint but rather as an example which opens up new imaginaries of what web systems designed within limits can be like. The fact that it is an example of a system with real use based on currently available technology further adds to this argument.

Considering the design was inspired by historic web development practices, a fruitful avenue for further research in to degrowth and ICT might be to look specifically at historical techniques within computing. That is because these techniques existed and functioned within contexts that were much less performant than contemporary ones. Given the performance boost resulting from using older technologies and techniques on newer infrastructure, these efficiency gains could be used not to increase the rate of computation or data throughput while maintaining the same energy footprint, but rather be used to bring down the energy cost of maintaining the same throughput instead. Similarly, learning from computational techniques and technologies developed in times when connectivity was not ubiquitous could yield further interesting results for contemporary designs based around unavailability.

\section{ACKNOWLEDGMENTS}

The research for https://solar.lowtechmagazine.com has been funded by Low-Tech Magazine and conducted when the author was an independent researcher. Many thanks to the rest of solar.lowtechmagazine.com team: Kris de Decker, Marie Otsuka and Lauren Traugott-Campbell. I'd also like to extend my gratitude to Cade Diehm (New Design Congress) and the reviewers Eli Blevis, Barath Raghavan and Douglas Schuler for their feedback on this article.

\section{REFERENCES}

[1] 2014. Mobile Basic by Facebook. https://mbasic.facebook.com/.

[2] 2018. Low-Tech Solutions. https://solar.lowtechmagazine.com.

[3] 2019. Instagram Loading Slow? Here's How to Make Instagram Android App Work Faster - Times of India. https://timesofindia.indiatimes.com/gadgetsnews/instagram-loading-slow-heres-how-to-make-instagram-android-appwork-faster/articleshow/69665760.cms.

[4] 2019. Media Links. https://solar.lowtechmagazine.com.
[5] 2020. Measurement \& Optimization. https://principles.green/principles/measurement/.

[6] 2020. Web Vitals. https://web.dev/vitals/.

[7] 2021. High Availability. Wikipedia (Jan. 2021).

[8] 2021. Page Weight. https://httparchive.org/reports/pageweight?start=2016_12_01\&end=latest\&view=list.

[9] 2021. PageSpeed Insights. https://developers.google.com/speed/pagespeed/ insights/?url=http://solar.lowtechmagazine.com/

[10] 2021. See Gmail in Standard or Basic HTML Version - Gmail Help. https://support.google.com/mail/answer/15049?hl=en.

[11] Samuel Alexander and Paul Yacoumis. 2016. Degrowth, Energy Descent, and 'Low-Tech' Living: Potential Pathways for Increased Resilience in Times of Crisis. fournal of Cleaner Production 197 (Sept. 2016). https://doi.org/10.1016/j.jclepro. 2016.09.100

[12] Franziska Verena Haucke. 2018. Smartphone-Enabled Social Change: Evidence from the Fairphone Case? fournal of Cleaner Production 197 (Oct. 2018), 17191730. https://doi.org/10.1016/j.jclepro.2017.07.014

[13] Lorenz Hilty. 2015. Computing Efficiency, Sufficiency, and Self-Sufficiency: A Model for Sustainability? (June 2015). https://doi.org/10.5167/uzh-110766

[14] Giorgos Kallis, Vasilis Kostakis, Steffen Lange, Barbara Muraca, Susan Paulson, and Matthias Schmelzer. 2018. Research On Degrowth. Annual Review of Environment and Resources 43, 1 (2018), 291-316. https://doi.org/10.1146/annurevenviron-102017-025941

[15] Christian Kerschner, Petra Wächter, Linda Nierling, and Melf-Hinrich Ehlers. 2018. Degrowth and Technology: Towards Feasible, Viable, Appropriate and Convivial Imaginaries. Journal of Cleaner Production 197 (Oct. 2018), 1619-1636. https://doi.org/10.1016/j.jclepro.2018.07.147

[16] Kris de Dekker. 2011. Insulation: First the Body, Then the Home. https://solar.lowtechmagazine.com/2011/02/body-insulation-thermalunderwear.html.

[17] Kris de Dekker. 2015. Restoring the Old Way of Warming: Heating People, Not Places. https://solar.lowtechmagazine.com/2015/02/heating-people-notspaces.html.

[18] Kris de Dekker. 2017. How to Run the Economy on the Weather. https://solar.lowtechmagazine.com/2017/09/how-to-run-the-economy-onthe-weather.html.

[19] Kris de Dekker. 2018. How to Build a Low-Tech Website? https://solar.lowtechmagazine.com/2018/09/how-to-build-a-lowtechwebsite.html.

[20] Kris de Dekker. 2018. Keeping Some of the Lights On: Redefining Energy Security. https://solar.lowtechmagazine.com/2018/12/keeping-some-of-the-lights-onredefining-energy-security.html.

[21] Kris de Dekker, Marie Otsuka, and Roel Roscam Abbing. 2019. How Sustainable Is a Solar Powered Website? https://solar.lowtechmagazine.com/2020/01/howsustainable-is-a-solar-powered-website.html.

[22] Marie Otsuka. 2018.2 Solar Web Design. https://github.com/lowtechmag/solar/wiki/Solar-Web-Design.

[23] Panos Petridis, Barbara Muraca, and Giorgos Kallis. 2015. Degrowth: Between a Scientific Concept and a Slogan for a Social Movement. Handbook of Ecological Economics (Sept. 2015).

[24] Chris Preist, Daniel Schien, and Eli Blevis. 2016. Understanding and Mitigating the Effects of Device and Cloud Service Design Decisions on the Environmental Footprint of Digital Infrastructure. In Proceedings of the 2016 CHI Conference on Human Factors in Computing Systems (San Jose, California, USA) (CHI '16). Association for Computing Machinery, New York, NY, USA, 1324-1337. https: //doi.org/10.1145/2858036.2858378

[25] Barath Raghavan and Daniel Pargman. 2017. Means and Ends in HumanComputer Interaction: Sustainability through Disintermediation. In Proceedings of the 2017 CHI Conference on Human Factors in Computing Systems (CHI '17). Association for Computing Machinery, New York, NY, USA, 786-796. https://doi.org/10.1145/3025453.3025542

[26] Roel Roscam Abbing. 2018. How to Build a Low-Tech Website: Software \& Hardware. https://homebrewserver.club/low-tech-website-howto.html. 